\title{
Predicting adverse maternal and perinatal outcome after threatened miscarriage
}

\author{
Swati Agrawal ${ }^{1,2^{*}}$, Susheela Khoiwal ${ }^{2}$, Kumar Jayant ${ }^{3}$, Rajendra Agarwal $^{2}$ \\ ${ }^{1}$ Obs \& Gynae, Rabindra Nath Tagore Medical College, Udaipur, India \\ ${ }^{2}$ Sudha Hospital and Medical Research Institute, 11-A Talwandi Kota, India \\ ${ }^{3}$ Postgradute Institute \& Medical Research Centre, Chandigarh, India \\ Email: drswatiagrawal2010@yahoo.co.in
}

Received 17 November 2013; revised 12 December 2013; accepted 20 December 2013

Copyright (c) 2014 Swati Agrawal et al. This is an open access article distributed under the Creative Commons Attribution License, which permits unrestricted use, distribution, and reproduction in any medium, provided the original work is properly cited. In accordance of the Creative Commons Attribution License all Copyrights (C) 2014 are reserved for SCIRP and the owner of the intellectual property Swati Agrawal et al. All Copyright (C) 2014 are guarded by law and by SCIRP as a guardian.

\section{ABSTRACT}

Objectives: Threatened miscarriage is the most common complication of pregnancy, occurring in $20 \%$ $25 \%$ of ongoing pregnancies. The purpose is to study maternal and perinatal outcome in women with threatened miscarriage. Methods: A prospective study was conducted over a period of 20 months in the Department of Obstetrics and Gynaecology, Pannadhay Mahila Chikitsalaya, a tertiary care center in Udaipur, India. It included a cohort of pregnant patients with a history of threatened miscarriage during the first twenty weeks of pregnancy. They were registered, followed up prospectively at antenatal clinics and delivered in the same hospital. For the purpose of comparison, another group of booked patients (controls) without a history of threatened miscarriage were recruited, similarly scanned and followed throughout pregnancy and labour. All women were matched for age, parity, social class, BMI and gestational age at booking. Discrete variables were taken as counts (or frequencies) and were evaluated by Chi-square test. Continuous variables with normal distribution were presented as mean \pm standard deviation (SD) and were compared by unpaired Student's t test. Data were fed into a Microsoft Excel worksheet and were analyzed by using the SPSS ver.17 (SPSS Inc., Chicago, IL, USA). $p$-value $>0.05$ was considered statistically significant. Results: Out of 62 cases, $13(21 \%)$ patients spontaneously aborted after diagnosis of threatened miscarriage. Women with threatened miscarriage had a significantly higher incidence of low lying placenta $(p=0.02)$ when compared with those without firsttrimester bleeding. They were more likely to experi-

*Corresponding author. ence PROM $(p=0.02)$, preterm delivery $(p=0.02)$ and to have babies with low Birthweight $(p=0.03)$. Conclusion: Pregnancies complicated by threatened miscarriage are at a higher risk for obstetric complications.

\section{KEYWORDS}

First-Trimester Bleeding; Threatened Miscarriage; Maternal Outcome; Perinatal Outcome; Subchorionic Hematoma

\section{INTRODUCTION}

First-trimester bleeding is a common complication which affects $20 \%$ - 25\% [1] of all pregnancies. Threatened miscarriage is diagnosed on the basis of documented fetal cardiac activity on ultrasound with a history of vaginal bleeding in the presence of a closed cervix [2]. In majority of the cases of threatened miscarriage, the bleeding is of unknown origin and usually slight. Ultrasonography confirms the diagnosis. It must reveal the fetus to show signs of life (e.g., heartbeat) [3]. USG may show subchorionic haematoma defined as a crescent shaped echo free area between the chorionic membrane and the myometrium [4]. In pregnancies where a hematoma is identified, the subjects should undergo repeated scans on a weekly basis until the hematoma resolves. Bleeding during pregnancy can cause maternal anxiety and emerging evidence suggests that it may be associated with poor fetal and maternal outcomes [5-13]. It is hypothesized that first-trimester bleeding may indicate an underlying placental dysfunction, which may manifest later in pregnancy causing adverse outcomes such as increased risk of pre-eclamptic toxemias (PET), preterm delivery, prelabour rupture of membranes (PROM), and intrauterine growth restriction 
(IUGR) [5]. Knowledge about the outcome of ongoing pregnancies following first-trimester bleeding is relevant to both women and their obstetricians in order to plan antenatal care and consider clinical interventions in pregnancy. Several primary studies have sought to identify adverse fetal outcomes, but very few have commented on maternal complications. Our objective is to study the maternal as well as perinatal complications in these pregnancies so that they can be managed in the best possible way with reduction in morbidity and mortality.

\section{MATERIALS AND METHODS}

This is a prospective study undertaken in the Department of Obstetrics and Gynaecology of a tertiary level health institute in Udaipur, Rajasthan, India after approval from the RNT Medical College Ethical Committee for Research Purpose. It was conducted over a period of 20 months from May 2011 to December 2012. After taking written informed consent, a cohort of 62 pregnant patients with bleeding per vaginum during the first twenty weeks of pregnancy were included. Such patients were registered, followed up prospectively at antenatal clinics and delivered at same hospital. The diagnostic criteria for threatened miscarriage were based on documented fetal cardiac activity on ultrasound with a history of vaginal bleeding in the presence of a closed cervix and gestational ageat 20 weeks or less. Other inclusion criteria were normal body mass index (BMI), reliable date of last menstrual period (LMP), previous regular cycles, uterine size corresponding to period of gestation, cervix uneffaced, closed internal os, without any cervical pathology; and single and viable pregnancy confirmed by ultrasound.

Pregnant females with chronic hypertension, diabetes mellitus, syphilis, thrombophilia, smoker, history of recurrent miscarriage, previous congenital malformations in children, history of trauma or surgery during the present pregnancy, cervical incompetence, congenital uterine anomalies, uterine fibroids or local cervical pathology like cervical polyp or erosion were excluded from our study.

The amount of bleeding was noted. If simply spotting, it was considered as light. If similar to patient's menstrual bleeding or more, it was considered as heavy. Ultrasonogram was performed for diagnosis, calculation of gestational age and to detect the presence of subchorionic hematoma. Patients with threatened miscarriage were managed with complete bed rest till 48 hrs of cessation of bleeding, folic acid supplementation, and were given tablet micronized progesterone $200 \mathrm{mg}$ bd.

For the purposes of comparison, another group of 55 booked patients without a history of threatened miscarriage (controls) was recruited, similarly scanned and followed throughout pregnancy and labour. They were ma- tched for age, parity, social class, BMI and gestational age at booking.

All patients had a complete examination (general, physical and gynaecological) at booking. The patients were followed up regularly every week in the antenatal clinic and repeat ultrasound scans were done as required. In patients with subchorionic hematoma, scans were repeated weekly until resolution of hematoma.

The outcomes measured were

Maternal complications-antepartum hemorrhage including placenta previa, placental abruption; preeclampsia, eclampsia; preterm labor (delivery between 20 and 36 weeks $+/-6$ days of gestation), prelabor rupture of membranes and mode of delivery.

Fetal complications-preterm, postdatism, congenital anomaly, stillbirth (antepartum or intrapartum death), early neonatal death, low birthweight (birthweight less than $2500 \mathrm{~g})$ and IUGR.

Detailed statistical considerations done before including

A priori power calculation to choose sample size

A description of the tests used to analyze results for each outcome

Anticipated effect size (Cohen’s d) :0.5

Desired statistical power level $\quad: 0.8$

Probability level $\quad: 0.05$

Minimum total sample size (one-tailed hypothesis): 102

Minimum sample size per group (one-tailed hypothesis): 51

Discrete variables were taken as counts (or frequencies) and were evaluated by Chi-square test. Continuous variables with normal distribution were presented as mean \pm standard deviation (SD) and were compared by unpaired Student's t test. Data was fed into a Microsoft Excel worksheet and was analyzed by using the SPSS ver. 17 (SPSS Inc., Chicago, IL, USA). $p$-value $<0.05$ was considered statistically significant.

\section{RESULTS}

103 women had threatened miscarriage but only 62 satisfied the inclusion criteria and therefore formed the study group. 41 were excluded because they either failed to attend follow up clinics, delivered at home or at other hospitals and rest were lost to follow-up. Similarly, 80 controls were recruited but only 55 were studied.

The women of the 2 groups did not have any significant differences in age, gravidity, BMI or gestational age at booking (Table 1 ).

There were more number of patients with light bleeding (43) as compared to heavy bleeding (19). Also there were more who bled in the first trimester (39) than who bled in second (23). 
Table 1. Comparative characteristics of both groups at the time of booking.

\begin{tabular}{cccc}
\hline Characteristics & $\begin{array}{c}\text { Study } \\
(\mathbf{n}=\mathbf{6 2})\end{array}$ & $\begin{array}{c}\text { Control } \\
(\mathbf{n}=\mathbf{5 5})\end{array}$ & $\boldsymbol{p}$-value \\
\hline Mean Age (years) & $23.85 \pm 3.48$ & $23.78 \pm 3.07$ & 0.86 \\
Mean BMI (kg/m $\left.\mathbf{m}^{2}\right)$ & $20.67 \pm 1.26$ & $20.53 \pm 1.43$ & 0.57 \\
Mean Gravidity & $1.85 \pm 1.02$ & $1.89 \pm 0.98$ & 0.84 \\
$\begin{array}{c}\text { Mean Gestational } \\
\text { Age at Booking } \\
\text { (weeks) }\end{array}$ & $11.21 \pm 3.23$ & $11.23 \pm 3.38$ & 0.77 \\
\hline
\end{tabular}

The overall adverse pregnancy outcomes were significantly higher in cases than the control group (Table 2). Incidence of spontaneous miscarriages was significantly higher in the cases.

Low lying placenta on USG at the initial scanning before 20 weeks was significantly more in cases than control group. But at term the difference was not significant which can partially be explained by theory of trophotropism of placenta.

The incidence of preterm labor, PROM, low birthweight was significantly higher among the cases. The mean birthweight and mean gestational age at birth was significantly less among cases.

Although the incidence of antepartum hemorrhage, preeclampsia, LSCS, IUGR, perinatal mortality, congenital anomaly was also higher among the cases but none of the values reached conventional levels of statistical significance.

Incidence of spontaneous miscarriage, PROM, preterm and low birthweight within cases were more common in patients with heavy bleed and in those who bled in first trimester, although not statistically significant.

Very high percentage (43.55\%) of patients had subchorionic hemorrhage on early USG in the study group while none in the control group had it. 37.04\% patients with hematoma aborted while only $8.57 \%$ of patients without hematoma aborted. This result was significant ( $p$ $=0.01$ ).

In patients with hematoma size $<4 \mathrm{~cm}^{2}, 82.35 \%$ continued pregnancy successfully till term and only $17.65 \%$ aborted while in cases with hematoma size $>4 \mathrm{~cm}^{2}$ spontaneous miscarriage was seen in as high as $70 \%$ patients $(p=0.02)$ (Table 3).

Incidence of IUGR was also higher in patients with subchorionic hematoma but the result was not significant.

\section{DISCUSSION}

The present study was conducted with an aim to find out effect of threatened miscarriage in the current pregnancy on the subsequent maternal and perinatal outcome.
Table 2. Comparative data of outcomes studied in both groups.

\begin{tabular}{|c|c|c|c|c|c|}
\hline Outcome & $\begin{array}{c}\text { Cases } \\
(n=49)\end{array}$ & $\%$ & $\begin{array}{l}\text { Control } \\
(\mathrm{n}=52)\end{array}$ & $\%$ & $p$-value \\
\hline $\begin{array}{l}\text { Spontaneous } \\
\text { Miscarriage }\end{array}$ & $13\left(n^{a}=62\right)$ & 21 & $3\left(n^{b}=55\right)$ & 5.45 & 0.03 \\
\hline $\begin{array}{l}\text { Low Lying } \\
\text { Placenta }\end{array}$ & $10\left(n^{a}=62\right)$ & 16.13 & $2\left(n^{b}=55\right)$ & 3.64 & 0.02 \\
\hline Placenta Praevia & 1 & 2.04 & 0 & 0 & 0.98 \\
\hline $\begin{array}{l}\text { Placenta } \\
\text { Abruptio }\end{array}$ & 3 & 6.12 & 1 & 1.92 & 0.57 \\
\hline PET & 3 & 6.12 & 2 & 3.85 & 0.95 \\
\hline PROM & 10 & 20.41 & 2 & 3.85 & 0.02 \\
\hline Preterm & 14 & 28.5 & 5 & 9.6 & 0.02 \\
\hline LSCS & 16 & 32.65 & 15 & 28.85 & 0.84 \\
\hline IUGR & 3 & 6.12 & 2 & 3.85 & 0.95 \\
\hline Postdatism & 3 & 6.12 & 4 & 7.69 & 0.76 \\
\hline $\begin{array}{c}\text { Mean } \\
\text { gestational } \\
\text { age at birth }\end{array}$ & 35.29 & & 38.11 & & 0.0002 \\
\hline $\begin{array}{c}\text { Mean } \\
\text { birthweight }\end{array}$ & 2.47 & & 2.94 & & 0.0001 \\
\hline $\begin{array}{l}\text { Perinatal } \\
\text { mortality }\end{array}$ & 4 & 8.16 & 3 & 5.77 & 0.91 \\
\hline $\begin{array}{c}\text { Congenital } \\
\text { anomaly }\end{array}$ & 1 & 2.04 & 0 & 0 & 0.98 \\
\hline Live birth & 47 & 95.92 & 49 & 0.67 & 0.67 \\
\hline Low Birthweight & 16 & 32.65 & 7 & 13.46 & 0.03 \\
\hline
\end{tabular}

a - total number of cases were 62 but 13 out of them aborted, so for all outcomes after 20 weeks total number of cases (n) were reduced to 49 . b - total number of controls were 55 but 3 out of them aborted, so for all outcomes after 20 weeks total number of controls (n) were reduced to 52 . We subtracted the number of patients who aborted for studying outcomes to obtain a more realistic data. c - perinatal mortality included IUD, intrapartum deaths and early neonatal deaths; among the cases there was 1 IUD, 1 intrapartum death and 2 early neonatal deaths; while among the controls all 3 were early neonatal deaths.

Table 3. Incidence of spontaneous miscarriage in relation to size of subchorionic hematoma.

\begin{tabular}{ccccccc}
\hline $\begin{array}{c}\text { Size of } \\
\text { hematoma }\end{array}$ & $\begin{array}{c}\text { Spontaneous } \\
\text { miscarriage }\end{array}$ & $\%$ & $\begin{array}{c}\text { Continuation of } \\
\text { pregnancy }\end{array}$ & \% & Total \\
\hline$<\mathbf{4} \mathbf{~ c m}^{2}$ & 3 & 17.65 & 14 & 82.35 & 17 \\
$>\mathbf{4} \mathbf{~ c m}^{2}$ & 7 & 70 & 3 & 30 & 10 \\
Total & 10 & & 17 & & 27 \\
\hline
\end{tabular}

$\mathrm{p}=0.02$.

We observed that the women of the 2 groups did not have any significant differences in age, gravidity, BMI or gestational age at booking. This data was consistent with the existing literature available [7,12-14].

In our study the overall adverse pregnancy outcomes were significantly higher in cases than the control group. 
Several studies have reported an association between first trimester bleeding and abnormal pregnancy outcome, including preterm deliveries, fetal growth restriction, and low Birthweight [5-13], but the majority of these reports, were retrospective, uncontrolled, or relied on patient recall recruiting later in the pregnancy. The largest prospective study was conducted by Weiss et al. [5] which concluded that first trimester bleeding was an independent risk factor for adverse obstetric outcome.

Subsequently we will deal each outcome one by one.

\subsection{Spontaneous Abortion}

An encouraging aspect of the current study is that patients with symptoms of threatened abortion and a living embryo that was documented are extremely likely to reach viability while the incidence of spontaneous abortion is quoted to be $50 \%$ before sonographic evaluation for fetal viability. The overall spontaneous abortion rate for the patients after a viable pregnancy was diagnosed on ultrasonography was $21 \%$ in cases and $5.45 \%$ in control group. This difference between the groups is statistically significant $(p=0.03)$. While in study by Weiss et al. the overall spontaneous pregnancy loss rate before 24 weeks of gestation was $0.5 \%$. This may be explained by the later recruitment of the cases, when many of the early miscarriages would have already occurred. Previous studies have also reported higher spontaneous abortion rates in study group compared to the control group [15-17].

\subsection{Low Lying Placenta and Placenta Previa}

The low lying placenta on USG at the initial scanning before 20 weeks was seen in $16.13 \%$ patients in cases and $3.64 \%$ patients in control group. This difference between the groups was statistically significant $(p=0.02)$. But when the incidence was compared at 36 weeks there was no significant difference $(p=0.98)$. Our findings concur with previous studies by Weiss et al. [5] and Das et al. [14]. This observation supports the concept of conversion of placental location with advancing gestational age for which different theories like placental migration, dynamic placentation and differential growth of lower uterine segment have been put forward. Whatever may be the mechanism involved, it operates in both groups. Thus it seems that low lying placenta plays a major role in causation of bleeding in early pregnancy. Weiss et al. [5] and Mulik et al. [8] observed a higher rate of placenta previa among patients with heavy vaginal bleeding during the first trimester.

\subsection{Preterm Labor and PROM}

Preterm delivery, is the leading cause of death of normal newborns [18]. Preterm premature rupture of membranes (PPROM) occurs in up to $40 \%$ of preterm deliveries
[19].

Our study indicates that women who have bleeding in the early pregnancy are at significantly increased risk of PROM (study group $=20.41 \%$ compared to $3.85 \%$ in control; $p=0.02)$ and preterm labor $(28.5 \%$ in cases and $9.6 \%$ in the control group; $p=0.02$ ). Our results are in agreement with the previous studies [5-7,13,15,20-24]. Similarly Saraswat et al. [23] in a meta analysis reported more likelihood to experience PPROM and preterm delivery in study group. Strobino et al. [9] failed to show an association between preterm delivery and threatened abortion.

Although the cause of PROM is unclear, it is hypothesized by Weiss et al. [5] that disruption of the chorionicamniotic plane by adjacent hemorrhage may make the membranes more susceptible to rupture by increased free radical production within the placental membranes. Alternatively, the prolonged presence of blood may act as a nidus for intrauterine infection. Persistent or recurrent placental hemorrhage could also stimulate subclinical uterine contractions resulting in cervical changes and eventual rupture of membranes.

Increased antenatal surveillance, possibly with cervical length measurements or the use of fetal fibronectin tests, might identify high risk cases within this group and will facilitate interventions, such as progesterone and antioxidant supplementation [25] from a much earlier gestation and also decision making regarding management, for example, timely administration of antibiotics and corticosteroids or regarding mode, place and timing of delivery, which will inevitably improve neonatal outcome [15].

\subsection{Low Birthweight}

Mean Birth weight is dependent on gestation, ethnicity, maternal weight and height. So all these confounding factors were standardised in both groups. Mean Birth weight was significantly lower in the cases $(2.47 \pm 0.69$ $\mathrm{kg})$ compared to controls $(2.94 \pm 0.16 \mathrm{~kg})(p=0.0001)$. Babies weighing less than $2500 \mathrm{~g}$ were twice more common in cases $(p=0.03)$. The difference in mean Birthweight seemed to be related to premature delivery, because a comparison of birthweights by gestation showed no difference between the groups, and the incidence of documented fetal growth restriction between the 2 groups was also not significant.

Dadkhah et al. [13] and Haddow et al. [26] also obtained similar results.

\subsection{Gestational Age at Birth}

In current study, the mean gestational age of patients in cases was $35.29 \pm 3.48$ weeks and $38.11 \pm 4.77$ weeks in control group. This difference between the groups is statistically significant $(p=0.0002)$ which may be partly 
due to higher incidence of preterm labor.

\subsection{Other Outcomes}

In the current study we observed no significant difference in the incidence of PET, abruptio placentae, postdatism, IUGR, congenital anomaly and perinatal mortality. Our data shows that the incidence of these complications were relatively increased, but not at significant levels matching with previous studies [5,12-14].

Saraswat et al. [23] in their systematic review observed that women with threatened miscarriage had a significantly higher incidence of antepartum haemorrhage and IUGR. Jacob et al. [24] and Ananth et al. [27] concluded that vaginal bleeding early in pregnancy are associated with increased risk of placental abruption in later pregnancy. Verma et al. [28] reported that PET was significantly more common in subjects with threatened abortion.

\subsection{Effect of Severity and Time of Bleeding on Pregnancy Outcome}

Incidence of spontaneous abortion, PROM, preterm and low Birthweight were more common in patients with 1st trimester bleed than 2nd trimester and in heavy bleeders than light bleeders within cases but none of the values reached conventional levels of statistical significance as a whole.

Similarly, Weiss et al. [5] and Chung et al. [29] have reported that the risk of fetal loss was directly proportional to the amount of vaginal bleeding but they found an increased risk of preeclampsia after light bleeding, but strangely not after heavy bleeding. Most of the studies have failed to distinguish between light and heavy bleeding.

\subsection{Subchorionic Hematoma}

Very high percentage (43.55\%) of patients had subchorionic hemorrhage on early USG in the cases while none in the control group had it which was similar to previous studies. In current study $83.33 \%$ of spontaneous abortion was seen in patients with subchorionic hematoma compared to $16.66 \%$ in patients with no hematoma even in cases which is statistically significant $(p=0.02)$. This result confirmed the findings of Bennet et al. [22]. The volume of hematoma influences the prognosis. Similarly, high incidence (70\%) of spontaneous abortion was seen with hematoma size $>4 \mathrm{~cm}^{2}$ and the rest $30 \%$ in patients with hematoma of size $<4 \mathrm{~cm}^{2}$. Similar were the results of previous studies.

\subsection{Mode of Delivery}

In our study the mode of delivery between the two groups was comparable. The incidence LSCS done for various indications in cases was $32.65 \%$ compared to
28.85\% in controls. This difference is not statistically significant ( $p=0.84$ ) concurring with previous literature $[13,14,23]$. In contrast Sipila et al. [7] reported a higher cesarean section rate in the cases with bleeding.

The variability of results obtained in different studies seemed to be due to lack of consistencies observed between these studies, in the definition of the upper limits of abortion used, size of the study population, gestational age at presentation and to a lesser extent the statistical test used. It appeared that the definitive relationship between threatened miscarriages and adverse pregnancy outcome is not yet established. The positive value of this assumption raises the awareness of practitioners of the possible complications that may follow.

\section{CONCLUSIONS}

To conclude, prematurity is the main poor outcome predicted following threatened miscarriage and this risk factor should be taken into consideration when deciding upon antenatal surveillance and management of these pregnancies. There is a need to monitor patients after a threatened miscarriage to minimise these complications, and such pregnancies demand more serious prenatal care. The identification of these high risk groups should enable better management protocols and new therapeutic protocols to improve neonatal outcome. While there was no significant increase in the incidence of antepartum haemorrhage, pregnancy induced hypertension, IUGR, perinatal mortality and congenital malformation. The most encouraging aspects of our study were that it was a prospective study, women were booked very early in pregnancy, multiple fetal as well as maternal outcomes were studied and weekly antenatal checkups of women in study group were done. This enabled us to detect the complications at the earliest and intervene appropriately.

With regard to the different studies, it seems reasonable to study further to find the best predictor for poor pregnancy outcome in women with threatened miscarriage. Investigations that determine the diagnostic and prognostic parameters are of value and more careful surveillance should be performed for them.

\section{CONFLICT OF INTEREST}

No author has any conflict of interest.

\section{FUNDING}

This research received no specific grant from any funding agency in the public, commercial, or not-for-profit sectors.

\section{REFERENCES}

[1] Farrell, T. and Owen, P. (1996) The significance of extra- 
chorionic membrane separation in threatened miscarriage. British Journal of Obstetrics and Gynaecology, 103, 926928. http://dx.doi.org/10.1111/j.1471-0528.1996.tb09915.x

[2] Cunningham, F.G., Gant, N.F., Leveno, K.J., et al. (2001) editors. William's obstetrics. 21st Edition, McGraw-Hill, New York.

[3] Park, I.Y., Park, C.H., Lee, G., et al. (2006) Prognosis of threatened abortion by embryonic/fetal heart beat rate. Ultrasound in Medicine \& Biology, 32, 264. http://dx.doi.org/10.1016/j.ultrasmedbio.2006.02.1204

[4] Mantoni, M. and Pedersen, J.F. (1981) Intrauterine haematoma: An ultrasonic study of threatened abortion. British Journal of Obstetrics and Gynaecology, 88, 47-51. http://dx.doi.org/10.1111/j.1471-0528.1981.tb00936.x

[5] Weiss, J.L., Malone, E.D., Vidaver, J., et al. (2004) Threatened miscarriage: A risk factor for poor pregnancy outcome, a population-based screening study. American Journal of Obstetrics \& Gynecology, 190, 745-750.

http://dx.doi.org/10.1016/j.ajog.2003.09.023

[6] Batzofin, J.H., Fielding, W.L. and Friedman, E.A. (1984) Effect of vaginal bleeding in early pregnancy on outcome. Obstetrics \& Gynecology, 63, 515-518.

[7] Sipila, P. and Hartikainen-Sorri, A.L. (1992) Perinatal outcome of pregnancies complicated by vaginal bleeding. BJOG, 99, 959-963. http://dx.doi.org/10.1111/j.1471-0528.1992.tb13697.x

[8] Mulik, V., Bethel, J. and Bhal, K. (2004) A retrospective population-based study of primigravid women on the potential effect of threatened miscarriage on obstetric outcome. Journal of Obstetrics \& Gynaecology, 24, 249-253. http://dx.doi.org/10.1080/01443610410001660724

[9] Strobino, B. and Pantel-Silverman, J. (1989) Gestational vaginal bleeding and pregnancy outcome. American Journal of Epidemiology, 129, 806-815.

[10] Funderburk, S.J., Guthrie, D. and Meldrum, D. (1980) Outcome of pregnancies complicated by early vaginal bleeding. British Journal of Obstetrics and Gynaecology, 87, 100-105. http://dx.doi.org/10.1111/j.1471-0528.1980.tb04500.x

[11] Hertz, J.B. and Heisterberg, L. (1985) The outcome of pregnancy after threatened abortion. Acta Obstetricia et Gynecologica Scandinavica, 64, 151-156. http://dx.doi.org/10.3109/00016348509154709

[12] Wijesiriwardana, A., Bhattacharya, S., Shetty, A., et al. (2006) Obstetric outcome in women with threatened miscarriage in the first trimester. Obstetrics \& Gynecology, 107, 557-562. http://dx.doi.org/10.1097/01.AOG.0000199952.82151.de

[13] F. Dadkhah, M. Kashanian and G. Eliasi (2010) Early human development, 86, 193-196. http://dx.doi.org/10.1016/j.earlhumdev.2010.02.005

[14] Das, A.G., Gopalan, S. and Dhaliwal, L.K. (1996) Fetal growth and perinatal outcome of pregnancies continuing after threatened abortion. Australian and New Zealand Journal of Obstetrics and Gynaecology, 36, 135-139. http://dx.doi.org/10.1111/j.1479-828X.1996.tb03269.x

[15] Johns, J. and Jauniaux, E. (2006) Threatened miscarriage as a predictor of obstetric outcome. Obstetrics \& Gynecology, 107, 845-850.

http://dx.doi.org/10.1097/01.AOG.0000206186.91335.9a

[16] Davari-Tanha, F., Shariat, M., Kaveh, M., et al. (2008) Threatened abortion: A risk factor for poor pregnancy outcome. Acta Medica Iranica, 46, 314-320.

[17] Tongsong, T., Srisomboon, J., Wanapirak, C., et al. (1995) Pregnancy outcome of threatened abortion with demonstrable fetal cardiac activity: A cohort study. Journal of Obstetrics \& Gynaecology, 21, 331-335. http://dx.doi.org/10.1111/j.1447-0756.1995.tb01019.x

[18] Copper, R.L., Goldenberg, R.L., Creasy, R.K., et al. (1993) A multicentre study of preterm birthweight and gestational age-specific neonatal mortality. American Journal of Obstetrics \& Gynecology, 168, 78-84. http://dx.doi.org/10.1016/S0002-9378(12)90889-3

[19] Parry, S. and Strauss, J.F. (1998) Premature rupture of the fetal membranes. The New England Journal of Medicine, 338, 663-670. http://dx.doi.org/10.1056/NEJM199803053381006

[20] Johns, J., Hyett, J. and Jauniaux, E. (2003) Obstetric outcome after threatened miscarriage with and without a hematoma on ultrasound. Obstetrics \& Gynecology, 102, 483-487. http://dx.doi.org/10.1016/S0029-7844(03)00580-5

[21] Williams, M.A., Mittendorf, R., Lieberman, E., et al. (1991) Adverse infant outcomes associated with first-trimester vaginal bleeding. Obstetrics \& Gynecology, 78, 14-18.

[22] Bennett, G.L., Bromley, B., Lieberman, E., et al. (1996) Subchorionic hemorrhage in first-trimester pregnancies: Prediction of pregnancy outcome with sonography. Radiology, 200, 803-806.

[23] Saraswat, L., Bhattacharya, S., Maheshwari, A., et al. (2010) Maternal and perinatal outcome in women with threatened miscarriage in the first trimester: A systematic review. BJOG, 117, 245-257. http://dx.doi.org/10.1111/j.1471-0528.2009.02427.x

[24] Jacob, A.L., Katrine, L.D., Ojvind, L., et al. (2010) Obstetrics and Gynecology, 115, 935-944.

[25] Da Fonseca, E.B., Bittar, R.E., Carvalho, M.H., et al. (2003) Prophylactic administration of progesterone by vaginal suppository to reduce the incidence of spontaneous preterm birth in women at increased risk: A randomized placebo-controlled double-blind study. American Journal of Obstetrics \& Gynecology, 188, 419-424. http://dx.doi.org/10.1067/mob.2003.41

[26] Haddow, J.E., Knight, G.J., Kloza, E.M., et al. (1986) Alpha-fetoprotein, vaginal bleeding and pregnancy risk. BJOG, 93, 589-593. http://dx.doi.org/10.1111/j.1471-0528.1986.tb07959.x

[27] Cande, V., Ananth, Y.O., Vinay, P., et al. (2006) Evidence of placental abruption as a chronic process: Associations with vaginal bleeding early in pregnancy and placental lesions. European Journal of Obstetrics \& Gynecology and Reproductive Biology, 128, 15-21. http://dx.doi.org/10.1016/j.ejogrb.2006.01.016

[28] Verma, S.K., Premi, H.K., Gupta, T.V., et al. (1993) Perinatal outcome of pregnancies complicated by threatened 
abortion. Journal of Indian Medical Association, 92, 364365.

[29] Chung, T.K.H., Sahota, D.S., Lau, T.K., et al. (1999) Threatened abortion: Prediction of viability based on signs and symptoms. Australian and New Zealand Journal of Obstetrics and Gynaecology, 39, 443-447.

http://dx.doi.org/10.1111/j.1479-828X.1999.tb03129.x

\author{
Abbreviations \\ USG: ultrasonography \\ PROM: prelabour rupture of membranes \\ IUGR: intrauterine growth restriction \\ BMI: body mass index \\ LMP: last menstrual period \\ PET: pre eclamptic toxemia \\ LSCS: lower segment cesarean section \\ LBW: low birth weight \\ SD: standard deviation
}

